\title{
The Effects of Multimedia Task-Based Language Teaching on EFL Learners' Oral L2 Production
}

\author{
Madhubala BavaHarji ${ }^{1}$, Mehrnaz Gheitanchian ${ }^{2}$ \& Krishnaveni Letchumanan ${ }^{1}$ \\ ${ }^{1}$ Learning Institute for Empowerment (LiFE), Multimedia University, Malaysia \\ ${ }^{2}$ Faculty of Creative Multimedia, Multimedia University, Malaysia \\ Correspondence: Krishnaveni Letchumanan, (LiFE), Multimedia University, FCM Building 3rd Floor, Persiaran \\ Multimedia, 63100 Cyberjaya, Selangor Darul Ehsan, Malaysia. Tel: 603-8312-5757. E-mail: \\ knaveni@mmu.edu.my
}

Received: January 15, 2014 Accepted: February 20, 2014 Online Published: March 6, 2014

doi:10.5539/elt.v7n4p11 URL: http://dx.doi.org/10.5539/elt.v7n4p11

\begin{abstract}
This study examined the effects of tasks, with varying levels of complexity, i.e. simple, + complex and ++ complex tasks on EFL learners' oral production in a multimedia task-based language teaching environment. 57 EFL adult learners carried out a total of 12 tasks, in sets of four tasks within three different themes and different levels of complexity. During the 16 weeks of the study, the students performed three oral test tasks that were assessed in terms of accuracy, fluency and complexity, using eight different measures. This study found that scaffolding learners in performing tasks with increasing levels of complexity in a multimedia task-based language teaching/learning context, results in improved second language oral production, particularly in terms of accuracy, fluency and complexity.
\end{abstract}

Keywords: multimedia task-based language teaching/learning, tasks with varying levels of complexity, EFL learners, accuracy, fluency, complexity

\section{Introduction}

The last two decades witnessed a growing attention to task-based language teaching and learning (Long, 1985; Ellis, 2003; Nunan, 2004; East, 2012). This surge of interest, according to Ellis (2005), is due to the fact that task-based language teaching (TBLT) is pertinent in both fields of second language (L2) pedagogy and L2 acquisition research. After years of research on TBLT in L2 context, researchers have presented predictable effects of different tasks (e.g. task conditions, task outcomes, aspects of task implementation, input variables) on various levels of L2 learners' performance (Gilabert, 2007; Kuiken \& Vedder, 2007a, 2007b; Robinson, 2007). Among the predictable effects include, allotting time for activities in the pre-task stage leads to both more fluent (Skehan \& Foster, 1997; Mehnert, 1998; Ortega, 1999) and more complex speech production during-the-task stage (Crookes, 1989; Foster \& Skehan, 1996; Ortega, 1999; Yuan \& Ellis, 2003; Gilabert, 2006). Robinson (2011) too found that a simple task leads to less complex language production, whilst a complex task elicits richer language production in terms of complexity in syntactic mode.

In order to maximize learners' opportunities to acquire L2 and be effective communicators, they would need to access extensive input (Krashen, 1981, 1994; Ellis, 2005). According to Ellis (2005, p. 21), "To ensure adequate access, teachers need to:

1) Maximize the use of L2 in the classroom. Ideally, [... L L2 needs to become the medium as well as the object of instruction [...];

2) Create opportunities for learners to receive input outside the classroom."

He believed that if more resources are available for students to refer to, even out of the classroom (especially for English as Foreign Language (EFL) learners), and that they know how to effectively use them, they would be able to achieve higher levels of L2 proficiency.

As a means of providing students with the different resources and opportunities to access a wide variety of input, even out of the classroom, this study incorporated multimedia technology, as a vehicle to transfer information properly (Clark, 1983, 1984; Pang, 2009) into the TBLT classroom. Moreno and Mayer (2007) believed that 
multimedia recitation and graphical illustration pro-create visual and mental models integrate with learners' prior knowledge (i.e. schema) to produce new knowledge. Mayer (2009) agreed that multimedia instruction (combining video, sound, words, and pictures together) would support meaningful learning as well as enable learners to understand the materials better. In support of the cognitive theory of multimedia, Mayer asserted (2004, p. 47), "People learn more deeply from words and pictures than from words alone."

Thus, the aim of this study was two-fold: to synergize the TBLT approach and multimedia technology to create a Multimedia Task-based Language Teaching (MMTBLT) environment to scaffold students' L2 oral production, and to examine the effects of MMTBLT on the L2 oral production, i.e. in terms of accuracy, fluency, and complexity.

\section{Method}

\subsection{Participants}

In Iran, students who pass the university entrance exam, but fail to meet the English requirement will have to attend the elementary general English course. The students who volunteered to participate in this study was made up of $57 \mathrm{EFL}$ adult university students (male/ female) who registered in the 16-week elementary general English course in a university in Iran. Their age ranged from 19 to 58 years old, with the mean age of 29.40. They would have undergone at least seven years of mandatory English classes at junior high and high schools before tertiary education. Based on a survey of the participants' background, their weekly formal English studying hours (not including this course of study) ranged from 0 to 4 hours per week, with a mean of 0.47 hours weekly. Data collected from the Nelson Proficiency Test (Version 050C), which is specifically designed for elementary level language learners found that the participants' recorded a mean score of 13.3 with a standard deviation of 2.9. The individual oral interviews, which was also conducted before the commencement of this study confirmed that their L2 proficiency level ranged from false beginners to pre-intermediate and their communicative skills in English were very limited. During the interview some of them merely smiled, without uttering a single word and most of them were unable to complete a full sentence in English. Examples of phrases that they were able to produce accurately were: My name is ... I am 22 years old (even some said, "I am 22 years!")

\subsection{Multimedia Tool}

A free web-based software program, which is a blogging tool and a Content Management System (CMS), was used as a medium to post instructional materials. The blog comprises texts, hypertexts, images (static or dynamic), and links to videos, audios, other web pages, and other files. This potentiality allowed the researchers to post the teaching and learning materials on the webpage. It created an environment that enabled students to have quick and easy access to the materials. In addition, a link was made available for student audience to post comments, questions, assignments and hold discussions. This feature was aimed at enabling students to stay "connected" to their instructor as well as to their peers.

\subsection{Tasks}

Taking into consideration the effects of topic familiarity on students' L2 acquisition (Ellis, 2003) and connectivity of ideas, we decided on three broad themes, i.e. Personal Life, Travel and World Events for this 16-week course of study (See Figure 1). In designing the 12 tasks (four for each theme), we also took into consideration the students' communicative needs, interests, ages and the effects of task contents on their performance (Cohen, Manion, \& Morrison, 2004). 


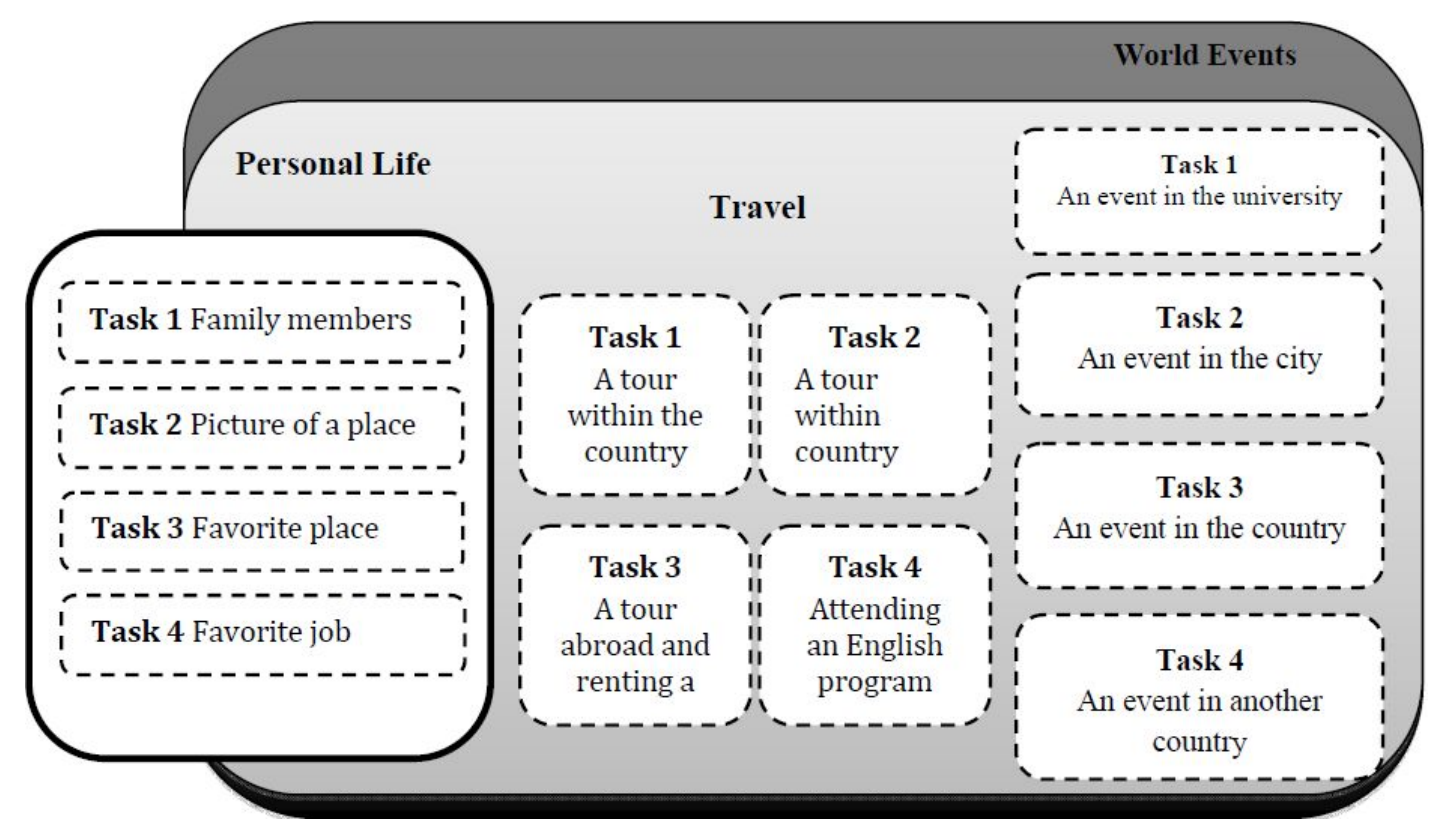

Figure 1. Themes and topics for tasks

In designing the tasks illustrated in Figure 1, as mentioned earlier we took into account several consideration in determining the themes and tasks. We decided to identify themes that would lend themselves well in designing tasks that would vary in levels of complexity. Firstly, we incorporated narratives, since narratives are said to help students learn morphological and syntactic structures that would prepare them to communicate beyond the classroom and in the real world (Kormos, 2011; Kiernan, 2003). Secondly, with the additional practices in performing tasks, which required them to tap on their previous knowledge, these tasks were designed to lend to automatization (Anderson, 2000). The tasks were also designed to draw the students' attention to the knowledge gap between their existing knowledge and the knowledge they need to perform the task in order to motivate them to acquire the structure (Kormos, 2011, p. 54). Skehan and Foster's (1997, 1999, 2001, 2005) studies reported that the types of tasks can also have an effect on the interlocutors' oral output, i.e. in terms of complexity, accuracy, and fluency.

In addition, adopting Robinson's Triadic Componential Framework (2001, 2003b, \& 2007) and Nunan's ranks of task difficulty (2004), we drew up tasks with different loads on students' cognitive resources. Nunan ranked task difficulties into three levels, i.e. "static", "dynamic", and "decision-making/abstract". Similarly, Robinson propounded the same classification along resource-directing dimension in his task complexity model, i.e. "+/Few elements", “+/- Here-and-now", and "+/- No reasoning". He believed combining or eliminating each of these elements affected task complexity. Synthesizing the two classifications, we categorized tasks within the personal life theme as "static" tasks and classified them under "+Here-and-now" category of resource-directing dimension in Robinson's task complexity model (See Table 1). These tasks were classified as simple tasks, since they imposed lesser cognitive load and required students to describe static situations. These tasks were carried out in the first phase of the study.

The tasks within the theme trip are reflective of Nunan's "dynamic" task ranks and were graded in the "-Here-and-now" category of resource-directing dimension in Robinson's model of task complexity. These tasks were categorized as +complex, since they required students to describe locations, states and activities that they performed earlier or would plan to do in the future. These tasks imposed slightly higher cognitive load on the students and were presented in the second phase of the study.

We regarded the tasks within the world events theme as "abstract" tasks, which Nunan ranked as the most difficult of all three task types. In addition, in incorporating Robinson's complexity model, i.e. "-Here-and-now" and "-No-reasoning" category, ++complex tasks were designed. These tasks required students to evaluate new information by stating reasons to support their views. ++complex tasks are deemed to impose the highest cognitive load on students and therefore were introduced in the last phase of the study. 
Table 1. Features and descriptions of sample treatment tasks

\begin{tabular}{lllll}
\hline Theme of Task & $\begin{array}{l}\text { Type of Task } \\
\text { Nunan's Task } \\
\text { difficulty }\end{array}$ & $\begin{array}{l}\text { Resource-directing } \\
\text { dimension } \\
\text { Robinson's } \\
\text { classification }\end{array}$ & $\begin{array}{l}\text { Complexity } \\
\text { level }\end{array}$ & Description of tasks \\
\hline Personal Life & Static & +Here-and-now & Simple & $\begin{array}{l}\text { Students to present factual } \\
\text { information about family } \\
\text { members }\end{array}$ \\
Trip & Dynamic & -Here-and-now & +Complex & $\begin{array}{l}\text { Students to talk about a trip } \\
\text { taken/to be taken }\end{array}$ \\
World's Events & Abstract & -Here-and-now & ++Complex & $\begin{array}{l}\text { Students to present a report } \\
\text { of a problem at the university, } \\
\text { giving at least two reasons } \\
\text { for cause of the problem and } \\
\text { suggest a solution for it }\end{array}$ \\
\hline
\end{tabular}

In addition to the levels of complexity, we also took into consideration the task conditions, i.e. "one-way", "open" and "divergent" (Ellis, 2003). According to Ellis, a "one-way" task places the responsibility of accomplishing it on a single person, who has to give information that s/he holds to complete it; "open" tasks are said to give students the opportunity to express their views in discussions, debates, surveys and other related activities and "divergent" tasks result in producing more words and greater output (Duff, 1986 in Ellis, 2003). Consequently, in order to increase students' involvement in the process of completing the tasks and eliciting more information from them, the 12 tasks were designed with the aforementioned features, namely: one-way, open and divergent.

\subsection{Blending Multimedia in Tasks}

As mentioned earlier, one of the aims of this study was to synthesize TBLT and multimedia, and the outcome is Multimedia Task Based Teaching and Learning (MMTBLT). In creating a rich MMTBLT environment, a web page was designed for students to access various materials related to the topic taught in each lesson. It was aimed at creating a virtual L2 environment, drawing students' attention and keeping them involved, encouraging them to participate and scaffolding their performance of the tasks. Each unit on the webpage was supplemented with various links and hyperlinks, which linked students to other sources of information in different web pages and various files. For instance, together with a text entitled "Describing Family Members", several links were made available to help students acquire additional information on the specific context: links that linked them to several pages, including a page with a word list related to introducing members and history of a family, a page that illustrates a family tree, a page where students can listen to a dialogue between two native speakers on a related topic, listening practices as well as a page that presents a sample of a student's oral production (Appendix 1). In addition, graphics, audio, video, plain texts, and other files were interlinked to create a non-linear medium of information. The embedded links and hyperlinks were aimed at linking students to various sources of information, to myriad materials for additional practice, such as several websites on free L2 instructional materials (www.englishclub.com, www.englishtenses.com, www.talkenglish.com etc.) as well as to free online dictionaries (e.g. Babylon Thesaurus, Babylon Dictionary, etc.) for their reference (See Appendix 2).

Generally, teaching materials for each lesson included a passage with a subject related to the main theme, links containing instructional materials to aid comprehension (e.g. related grammatical points), links containing supplementary materials (e.g. listening texts, related games, self-assessment tests, etc.), and assigned tasks to be carried out as class activities or homework. The objectives of the tasks were two-folded: first, to develop students' production skills, with the focus on oral production; and second, to scaffold students' communicative L2 skill to enable them to converse in a real world environment. The take-home tasks were published on the webpage for students to view their peers' assignments, comment on the tasks, give feedback or elicit ideas.

To scaffold students' performance of the tasks, the researchers composed 12 passages, which were proofread and validated by four ELT experts, and piloted with elementary level students (since, as mentioned earlier, the participants of this study were at the elementary level) in both EFL and ESL contexts. Each series of passages was a structured cluster of ideas in the same genre, but different topics to help students construct their own piece 
of knowledge and scaffold the performance of the oral tasks they would have to carry out at the end of each phrase of the study.

\subsection{Oral Test Tasks}

In order to assess the individual students' levels of accuracy, fluency and complexity of oral L2 production, three oral production test tasks, at various levels of complexity within the multimedia task based context, were designed. The topics for the test tasks were "telling a story with "you" as the main character", "talking about a trip that you have written in your journal", and "talking about a critical piece of news". Each test was a task, which was individually performed after every four sessions of the study, so that the students were required to carry out the tasks within the same category and theme. All the tasks were analyzed using the measures of accuracy, fluency and complexity. Figure 2 illustrates the oral production test tasks each student performed in the course of this study.

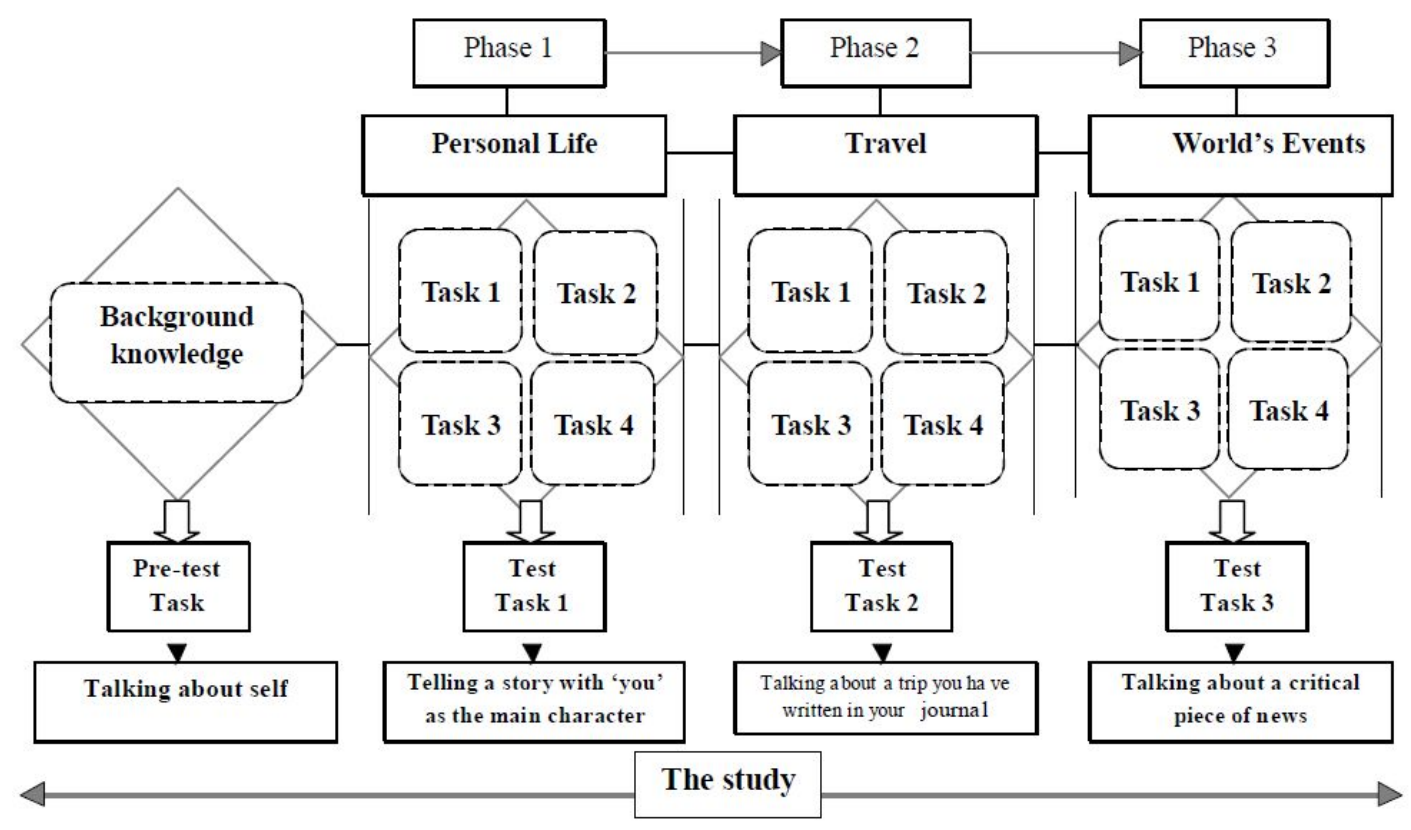

Figure 2. Oral production test tasks

As seen in Figure 2, the same topic was identified for the pre-test and the first test to measure the effects of simple tasks during the first phase of the study on the students' oral L2 production. After carrying out simple tasks on various topics during the first four sessions within the theme of "Personal Life", the students were assigned to compose a story of themselves and perform the task orally, using the knowledge they had gained in the first phase of the study. "A story about self" was categorized as a "simple task" since the students were required to construct factual sentences (i.e. +Here-and-now) to compose their stories. The students' tasks were analyzed, using the measures of accuracy, fluency, and complexity to assess the effects of simple tasks on the students' oral L2 production in the MMTBLT context.

At the end of the second phase of the study, the students performed +complex tasks on the theme, Travel. They were assigned to prepare a journal about a trip they made and present it orally as the second test task. "A travel journal" was categorized under "+complex" task since the students were required to construct several sentences, based on an event in the past (i.e. -Here-and-now). The students' oral presentation of their journals were analyzed, using the same measures of accuracy, fluency and complexity to examine the effects of + complex tasks on the students' oral L2 production in the MMTBLT context.

The final test examined the effects of ++complex tasks on the students' oral L2 production in the MMTBLT environment. They were assigned to write a piece of news about an event and present it orally as the third test task. They were asked to include at least three reasons for the event and offer solutions. "A critical piece of news" was placed under the "++complex" task category, since the students were required to gather information about an event that happened in the past and offer reasoning (i.e. -Here-and-now and -No-reasoning). 


\subsection{Procedure}

As mentioned earlier this was conducted over a 16 week period, was held once a week for two and a half hours per session in the computer lab. Due to the insufficient number of computers, the students worked in pairs or small groups (3-4 students in each group). As stated earlier, the Nelson proficiency test was administered to gauge the students' proficiency level before the study. They were also briefed on the MMTBLT context, the multimedia tasks as well as how to present the tasks oral. Table 2 illustrates the schedule of the classroom procedure during the course of study.

Table 2. Classroom procedure schedule

\begin{tabular}{|c|c|c|c|c|}
\hline Week & Phase & $\begin{array}{l}\text { Complexity } \\
\text { level }\end{array}$ & $\begin{array}{l}\text { Treatment } \\
\text { Task }\end{array}$ & Procedure \\
\hline 1 & I & - & - & $\begin{array}{l}\text { Oral production test (pre-treatment test) Nelson } \\
\text { Proficiency test }\end{array}$ \\
\hline 2 & I & simple & 1 & Describing family members \\
\hline 3 & I & simple & 2 & Describing a picture of a place \\
\hline 4 & I & simple & 3 & Describing their favorite place \\
\hline 5 & I & simple & 4 & Describing their favorite job \\
\hline 6 & I & - & - & Students' First Oral Presentation \\
\hline 7 & II & +complex & 1 & Traveling in a city within the country \\
\hline 8 & II & + complex & 2 & Traveling in the country with an international friend \\
\hline 9 & II & +complex & 3 & Traveling abroad and rent a hotel room \\
\hline 10 & II & + complex & 4 & Attending an English program abroad \\
\hline 11 & II & - & - & Students' Second Oral Presentation \\
\hline 12 & III & ++ complex & 1 & Sharing an event in the university \\
\hline 13 & III & ++ complex & 2 & Sharing an event in the city \\
\hline 14 & III & ++ complex & 3 & Sharing an event in the country \\
\hline 15 & III & ++ complex & 4 & Sharing an event in another country \\
\hline 16 & III & - & - & Students' Final Oral Presentation \\
\hline Total & & & 12 & \\
\hline
\end{tabular}

As seen in Table 2, each phase of the study was over four weeks and during each phase the students were given four different tasks in the same genre, with different topics and different levels of complexity, followed by an oral presentation to assess the changes in the students' oral L2 production in the MMTBLT context.

\subsection{Data Source}

Ellis (2003) presented a list of measures to examine accuracy, fluency, and complexity levels of oral L2 production. Since consideration of various measures in order to evaluate accuracy, fluency, and complexity of oral L2 production makes cross study comparison complicated and does not lead to a reliable result (Dembovskaya, 2009), several measures which were adopted in other studies and showed sensitivity in capturing variance were also adopted in this study. The measures are discussed in the following sections.

\subsubsection{Measures of Accuracy}

In a study, Ellis and Yuan (2005) examined the students' accuracy level, by considering the percentage of error-free clauses in their speech. Foster and Skehan applied this measure in different studies in 1996 and 1999 and stated that the percentage of error-free clauses was a sensitive measure to reveal students' speech differences.

Taking into consideration the students' English proficiency level ranged from false beginners to pre-intermediate level (based on the Nelson Proficiency Test result), we decided to adopt a generalized measure, i.e. percentage of error-free clauses as well as two more specific measures to examine the students' accuracy levels. Hence following three measures were adopted:

1) Percentage of error-free clauses

2) Target-like use of verb tenses 


\section{3) Target-like use of plurals}

\subsubsection{Measures of Fluency}

According to Saville-Troike (2012, p. 80), "fluency is achieved in production [...] through use of automated rule-based systems". Similarly, Schmidt (1992, pp. 358-359) referred to fluency as "automatic procedural skill" that showed the speech which was easily and automatically produced with no effort and attention (Wood, 2010). Ellis (2003) listed several measures to examine the fluency levels of oral L2 production. Total number of pauses is one of the measures, which was used in several studies (Foster \& Skehan, 1996, 1999; Mehnert, 1998; Dembovskaya, 2009) showed significant differences in the students' fluency. Hence, to examine the students' language fluency, we decided to adopt the following measures:

1) Number of pauses per 90 seconds

2) Number of words per 90 seconds

\subsubsection{Measures of Complexity}

Foster and Skehan (1999) found that the number of clausal subordination is a reliable measure which showed sensitivity in various experimental contexts and were correlated with other complexity measures. Dembovskaya (2009), who reported its reliability, had employed this measure in his study. Based on previous studies (Mehnert, 1998; Yuan \& Ellis, 2003; Larsen-Freeman, 2006) and the proficiency levels of the participants before the study, the following three measures were employed in this study:
1) Amount of clausal subordination
2) Frequency of use of conjunctions
3) Frequency of use of prepositions

In sum, we employed eight measures to examine the students' L2 oral production, particularly in terms of accuracy, fluency and complexity.

\subsection{Data Coding}

To examine individual students' accuracy, fluency and complexity level of their oral L2 production, audio and video recordings of their presentations were transcribed and coded for the eight different measures. 90 seconds of each presentation was analyzed, which began in the middle of the presentations (i.e. from the second 91). This was because most of the students were nervous at the beginning of the presentation and nervousness resulted in lots of pauses, repetitions and false starts. In Ellis's (2003) classification of production variables, the productions were analyzed per minute, but since most of the participants in this study were false beginners and some were performing oral presentations in English for the very first time, we decided to measure their production for the duration of 90 seconds for more reliable results, rather than less than 90 seconds.

We developed a coding system to ensure reliability. In a coordination meeting, the four independent raters, who coded the data discussed to finalize the coding system of the oral production. Once consensus was made, the raters individually coded approximately 20 per cent of the data. The level of agreement among them was thereafter calculated, using Kappa Coefficient for all the eight measures for accuracy, fluency and complexity. According to the interpretation of Kapa (Viera \& Garrett, 2005), the level of agreement among the four raters was considered as "very good". Table 3 shows the levels of agreement between the raters

Table 3. Levels of agreement between the raters

\begin{tabular}{lll}
\hline Dimension & Measure & Kappa agreement value \\
\hline \multirow{3}{*}{ Accuracy } & Percentage of error-free clauses & 1.000 \\
& Target-like use of verb tenses & 1.000 \\
& Target-like use of plurals & 0.833 \\
\hline \multirow{2}{*}{ Fluency } & Number of words per minute & 1.000 \\
& Number of pauses per minute & 0.839 \\
\hline \multirow{3}{*}{ Complexity } & Amount of clausal subordination & 0.808 \\
& Frequency of use of conjunctions & 1.000 \\
& Frequency of use of prepositions & 1.000 \\
\hline
\end{tabular}




\subsubsection{Accuracy}

To acquire the percentage of error-free clauses, the number of error-free clauses was divided by the total number of clauses and multiplied by 100 (Yuan \& Ellis, 2003; Dembovskaya, 2009). Errors in syntax, morphology, and lexical choices were considered. As per Foster and Skehan (1996), and Dembovskaya (2009), lexical errors were recorded when a word was absolutely wrong, but not in cases of fine appropriateness of a word in a sentence. For instance, the choice of word "beautiful" in the sentence "My brother is a beautiful man" was not considered as an error.

To examine target-like use of verb tenses in the students' utterances, the correct use of the verb tenses was considered (e.g. "My brother leave school at 1:00 pm every day."; "We take a trip to Antalia last summer."). To assess the number of target-like use of plurals, the correct use of plural nouns in the sentence (e.g. women not womans) and the subject-verb agreement (e.g. "My friend and I are [not am] talking about a trip now.") were counted.

\subsubsection{Fluency}

The number of trimmed words, which was counted, referred to the deletion of words, which were repeated, self-corrected and addressed to the instructor. In terms of pauses, those that took two seconds or more were taken into consideration throughout the 90 -second oral production.

\subsubsection{Complexity}

The amount of clausal subordination was defined as the number of dependent clauses per 90 seconds of participants' oral production. In addition, any incomplete clauses or clauses with errors within the verb phrase boundaries were excluded from the count. Frequency of use of conjunctions and prepositions were considered since the students were able to produce only short/simple sentences before this study. Therefore, counting the number of conjunctions and prepositions was deemed as an appropriate criterion to show any improvement in complexity level of the students in their oral production.

\section{Results}

After analyzing the data using the eight measures (percentage of error-free clauses; target-like use of verb tenses; target-like use of plurals; number of words per 90 seconds; number of pauses per 90 seconds; amount of clausal subordination; frequency of conjunctions; frequency of use of prepositions) a statistical tool of MANOVA analysis, followed by "Factor Analysis" was used to attain the mean scores of students' accuracy, fluency and complexity between the pre-test tasks and the three test-tasks performed after each phase of the study.

Firstly, the result, of the Multivariate test, with the significance of 0.000 and value of .008 for Wilk's lambda affirmed that the treatments applied during the course of study affected on at least one of the eight focused areas of the students' oral L2 production in the three categories of accuracy, fluency, and complexity (See Table 4).

Table 4. Multivariate test comparing the mean scores of 8 subcategories of accuracy, fluency, complexity

\begin{tabular}{llll}
\hline Effect & Value & F & Sig. \\
\hline Treatment & & & \\
Wilks'lambda & .008 & 85.432 & .000 \\
\hline
\end{tabular}

Secondly, a Duncan Multiple Range test (followed by MANOVA repeated measure) was also run. Using the statistics of "principled component", the weighted means of students' accuracy, fluency and complexity that were obtained from the eight measures in each phase of study was calculated and compared by running a Duncan Multiple Range test, using SPSS 16.0.

\subsection{Accuracy}

The results of the effects of the treatment tasks on the accuracy of oral L2 production, using the three measures: percentage of error-free clauses, target-like use of verb tenses and target-like use of plurals are presented in Table 5. 
Table 5. The result of Duncan multiple range test on accuracy of L2 production

\begin{tabular}{|c|c|c|c|c|c|c|}
\hline \multirow{2}{*}{ Treatment phase } & \multirow{2}{*}{$\begin{array}{l}\text { Type of treatment } \\
\text { task }\end{array}$} & \multirow{2}{*}{$\mathrm{N}$} & \multicolumn{4}{|l|}{ Subsets } \\
\hline & & & 1 & 2 & 3 & 4 \\
\hline Pre-treatment & & 57 & 1.5957 & & & \\
\hline 1 & simple & 57 & & 5.0557 & & \\
\hline 2 & +complex & 57 & & & 6.2308 & \\
\hline 3 & ++ complex & 57 & & & & 8.6060 \\
\hline Sig. & & & 1.000 & 1.000 & 1.000 & 1.000 \\
\hline
\end{tabular}

The Table displays the mean scores of the students in homogeneous subsets for each phase of the study. As we can see, there is obvious increase in the accuracy levels after the treatment of simple tasks. The mean score of the students' accuracy level before the treatment was less than $2(M=1.5957)$, however after the first treatment tasks (simple tasks); there is an increase in the mean score to 5.0557, with a mean difference of 3.460. At the end of the second phase of the study (+complex tasks) the mean score was 6.2308 and after the final phase of the treatment $(++$ complex tasks), the mean score recorded is 8.6060 .

\subsection{Fluency}

The results of the effects of the treatment tasks on the fluency of oral L2 production, using the two measures: number of words per 90 seconds and number of pauses per 90 in seconds are presented in Table 6.

Table 6. The result of Duncan multiple range test on fluency of L2 production

\begin{tabular}{|c|c|c|c|c|c|c|}
\hline \multirow{2}{*}{ Treatment phase } & \multirow{2}{*}{$\begin{array}{l}\text { Type of treatment } \\
\text { task }\end{array}$} & \multirow{2}{*}{$\mathrm{N}$} & \multicolumn{4}{|l|}{ Subsets } \\
\hline & & & 1 & 2 & 3 & 4 \\
\hline \multicolumn{7}{|l|}{ Pre-treatment } \\
\hline 1 & & 57 & 13.5993 & & & \\
\hline 2 & simple & 57 & & 23.9966 & & \\
\hline \multirow[t]{2}{*}{3} & +complex & 57 & & & 37.9120 & \\
\hline & ++ complex & 57 & & & & 61.2685 \\
\hline Sig. & & & 1.000 & 1.000 & 1.000 & 1.000 \\
\hline
\end{tabular}

As seen in the Table, the mean score of the students' fluency level in before the first treatment is 13.5993, but after the first phase of treatment of simple tasks, the mean score increased to 23.9966, with a mean difference of 10.3973. At the end of the second phase of the study of +complex tasks, the mean score increased further to 37.9129 and at the end of the treatment of the ++ complex tasks, the highest mean score recorded is 61.2685.

\subsection{Complexity}

The results of the effects of the treatment tasks on the complexity of oral L2 production, using the three measures: amount of clausal subordination, frequency of conjunctions, and frequency of use of prepositions are presented in Table 7.

Table 7. The result of Duncan multiple range test on complexity of L2 production

\begin{tabular}{|c|c|c|c|c|c|c|}
\hline \multirow{2}{*}{ Treatment phase } & \multirow{2}{*}{$\begin{array}{l}\text { Type of treatment } \\
\text { task }\end{array}$} & \multirow{2}{*}{$\mathrm{N}$} & \multicolumn{4}{|c|}{ Subsets } \\
\hline & & & 1 & 2 & 3 & 4 \\
\hline Pre-treatment & & 57 & 1.5896 & & & \\
\hline 1 & simple & 57 & & 4.2966 & & \\
\hline 2 & +complex & 57 & & & 6.0006 & \\
\hline 3 & ++ complex & 57 & & & & 13.2898 \\
\hline Sig. & & & 1.000 & 1.000 & 1.000 & 1.000 \\
\hline
\end{tabular}

As seen in the Table, the mean scores of the students' level of complexity of their oral production before the treatment is 1.589 and after the first treatment tasks (simple tasks), the mean score is 4.2966 , with a mean 
difference of 2.707. At the end of the second phase of the study (+complex tasks) and third phase of the treatment (++complex tasks), the mean scores attained are 6.0006 and 13.2898 respectively.

\section{Discussion}

The results of this study show that incorporating multimedia in the task-based language teaching environment, with varying levels of complexity, has an effect on improving students' oral L2 production in terms of accuracy, fluency, and complexity, specifically in the measures tested. The following highlights the discussions on the effects of MMTBLT environment on students' accuracy, fluency, and complexity respectively.

\subsection{Accuracy}

Giving students tasks with increasing degree of complexity, with the support of multimedia tool as the medium of instruction in the MMTBLT context, the students appear to be able to produce more accurate language. The result showed an obvious increase in the students' accuracy, as reflected in the increase in mean scores of the students' levels of accuracy throughout the study. The results showed improvement in accuracy level after the first phase of treatment tasks $(\mathrm{M} 0=1.60<\mathrm{M} 1=5.05)$. Although the progress of the students after the second phase of the treatment was not as obvious as compared to their progress after the first and third phases of the study, the difference between the students' accuracy before treatments and after the final phase of treatment is substantial $\left(\mathrm{M}_{0}=1.60, \mathrm{M}_{3}=8.61 ; \mathrm{MD}=7.01\right)$.

Although Robinson (2003b, 2005a) found that increasing task complexity along resource-directing dimension and making tasks more complex would result in more accurate language production, this study found that even after performing simple tasks at the first phase of the study, the students' oral L2 production showed considerable improvement in accuracy $(\mathrm{M} 1-\mathrm{M} 0=3.46)$. This result could be due to the factors which were taken into consideration in the process of designing the MMTBLT tasks. As mentioned earlier, topic familiarity, connectivity of ideas, and using narratives may have possibly helped students learn syntactic structures that lead to the production of more accurate L2. In addition, integrating multimedia in the TBLT context increased the amount of exposure to language and gave students opportunities to access various data within the same theme. This resulted in repetition of ideas and would have been a good practice for the students to develop the accuracy of their oral L2 production. In general, the result of the study is consistent with Robinson's findings as the mean scores attained increased throughout the course of study as the levels of complexity of tasks increased. The mean difference before and at the end of the treatment recorded for fluency was 47.6692 .

\subsection{Fluency}

The results also showed that increasing task complexity along resource-directing dimension in the MMTBLT context was effective in developing fluency in oral L2 production. Similar to accuracy of oral production, there was an obvious improvement in the students' fluency of oral production. The mean score of the students' final presentations shows an apparent improvement $\left(\mathrm{M}_{0}=13.60<\mathrm{M}_{1}=24.00<\mathrm{M}_{2}=37.91<\mathrm{M}_{3}=61.27\right)$. In general, the results show that the treatment tasks, with varying degrees of complexity aids fluency of oral L2 production in the MMTBLT environment. With the increase exposure to the language in each phase of the study, students were exposed to the same genre and were given the opportunity to receive repeated messages, which would have attributed to increased vocabulary and cognizant of language functions. This would have developed their confidence to speak in L2. In addition, the MMTBLT environment created opportunities for the students to communication frequently with their peers and the instructor, which may have attributed to increased elicitation of speech during the 16-week of the study. It was a good practice to develop fluency as seen in the mean difference before and at the end of the treatment recorded for accuracy, $\mathrm{MD}=11.70$.

\subsection{Complexity}

As seen in the results presented in Table 6, the students were also able to produce increasing levels of complex language throughout the course of study. The mean score of the students' final presentations shows an obvious improvement in the students' complexity of oral production $\left(\mathrm{M}_{0}=1.59<\mathrm{M}_{1}=4.30<\mathrm{M}_{2}=6.00<\mathrm{M}_{3}=13.29\right)$. The findings concur with Robinson (2003b, 2005a), i.e. increasing the complexity of tasks along resource-directing dimensions can set more linguistically complex structure in target language. In other words, increasing complex task demand leads to more complex language production. The results of this study clearly show that increasing task complexity along resource-directing dimension in the MMTBLT context improves the students' complexity of their oral production. It also indicates that in an MMTBLT context, even simple tasks can develop the complexity level of oral L2 production. Notwithstanding the fact that simple tasks can be more effective than + complex tasks in developing language complexity $\left(\mathrm{M}_{1}-\mathrm{M}_{0}=2.71>\mathrm{M} 2-\mathrm{M} 1=1.50\right)$, the results show that ++ complex tasks can have obvious effects on developing complexity of oral L2 production $\left(\mathrm{M}_{3}-\mathrm{M}_{2}=\right.$ 
7.29).

In comparing the three components of oral L2 production, i.e. accuracy, fluency, and complexity, examined in this study, we found that the effects of MTBLT is greater on fluency of oral L2 production, followed by complexity and accuracy of oral L2 production. However, we acknowledge that the measures used for each component vary in aspects measured.

In sum, the results of the study is consistent with the outcome of previous research (Robinson, 2001; Dembovskaya, 2009) and evinced increasing the complexity of tasks in MMTBLT context can enhance complexity level of students' oral L2 production.

\section{Conclusion}

This study has shown that the MMTBLT approach improves oral L2 language production, particularly in enhancing students' language accuracy, fluency and complexity. This approach builds a bridge between the TBLT context and the world of technology by incorporating multimedia in a teaching approach, which has been recently gaining popularity in EFL/ESL context. The MMTBLT approach can be used in various teaching contexts with different purposes, focusing on different aspects of the language. This study provides evidence for EFL instructors to consider in designing materials for multimedia-incorporated classrooms to support students along the journey through inter-language path to produce more accurate, fluent and complex L2. Possible areas for further research include changing the task complexity along resource dispersing dimension to examine its effects on students' oral L2 improvement. In addition, multimedia technology can be blended in other types of tasks to examine its effect the on students' L2 development. Using other features of the tasks, lengthening the duration of the treatment, using authentic materials instead of self-designed tasks could lead to different results. Finally, future studies could also adapt the context (i.e. EFL context), age group of participants and types of measures to examine the students' accuracy, fluency and complexity level.

\section{References}

Anderson, E. (2000). The future of library automation for schools. School Libraries in Canada, 20(1), 9-10.

Clark, R. E. (1983). Reconsidering Research on Learning from Media. Review of Educational Research, 53(4), 445-459.

Clark, R. E. (1984). Research on student thought processes during computer-based instruction. Journal of Instructional Development, 7(3), 2-5. http://dx.doi.org/10.1007/BF02905752

Cohen, L., Manion, L., \& Morrison, K. (2004). A Guide to Teaching Practice (4th ed.). Routledge Falmer, NY.

Crookes, G. (1989). Planning and interlanguage variation. Studies in Second Language Acquisition, 11(4), 367-383. http://dx.doi.org/10.1017/S0272263100008391

Dembovskaya, S. B. (2009). Task-based instruction: The effect of motivational and cognitive pre-tasks on second language oral French production ( $\mathrm{PhD}$ dissertation, University of Iowa). Retrieved from http://ir.uiowa.edu/etd/231/

East, M. (2012). Task-based language teaching from the teachers' perspective: Insights from New Zealand. Library of Congress Category-in- Publication data. http://dx.doi.org/10.1075/tblt.3

Ellis, R. (2003). Task-based language learning and teaching. Oxford University Press.

Ellis, R. (2005). Section A: Learning principles and aspect: Principles of instructional language learning. In P. Robertson (Ed.), English language learning in the Asian context (2nd ed.). Asia EFL Journal Press.

Ellis, R., \& Yuan, F. (2005).The effects of careful within-task planning on oral and written task performance. In R. Ellis (Ed.), Planning and task performance in a second language (pp. 167-192). Amsterdam: John Benjamins Publishing Company.

Foster, P., \& Skehan, P. (1996). The influence of planning on performance in task-based learning. Studies in Second Language Acquisition, 18, 299-324.

Foster, F., \& Skehan, P. (1999). The influence of source of planning and focus on task-based performance. Language Teaching Research, 3(3), 215-247. http://dx.doi.org/10.1177/136216889900300303

Gilabert, R. (2006). The simultaneous manipulation of task complexity along planning time and (+/-Here-and-Now): Effects on L2 oral production. In M. P. García-Mayo (Ed.), Investigating tasks in formal language learning. Multilingual Matters LTD. Library of Congress Category-in- Publication data.

Gilabert, R. (2007). The simultaneous manipulation of task complexity along planning and +/- Here-and-Now: 
effects on L2 oral production. In M. P. García-Mayo (Ed.), Investigating tasks in formal language learning. Clevedon: Multilingual Matters.

Viera, J. A., \& Garrett, J. M. (2005). Understanding interobserver agreement: The kappa statistic. Journal of Family Medicine, research series, 37(5).

Kormos, J. (2011). Task complexity and linguistic and discourse features of narrative writing performance. Journal of Second Language Writing, 20(2), 148-161. http://dx.doi.org/10.1016/j.jslw.2011.02.001

Kiernan, P. (2003). Narrative tasks in communicative language learning (pp. 299-306). JALT in Shizuka, conference proceeding.

Krashen, S. (1981). Second Language Acquisition and Second Language Learning. Oxford: Pergamon.

Krashen, S. (1994). The input hypothesis and its rivals. In N. Ellis (Ed.), Implicit and Explicit Learning of Languages. London: Academic Press.

Kuiken, V., \& Vedder, I. (2007a). Cognitive task complexity and linguistic performancein French L2 writing. In M. P. García-Mayo (Ed.), Investigating Tasks in Formal Language Learning (pp. 117-135). Clevedon: Multilingual Matters.

Kuiken, V., \& Vedder, I. (2007b). Task complexity and measures of linguistic performance in L2 writing. IRAL, International Review of Applied Linguistic in Language Teaching, 45(3), 261-284.

Larsen-Freeman, D. (2006).The emergence of complexity, fluency, and accuracy in the oral and written production of five Chinese learners of English. Applied Linguistics, 27(4), 590-619. http://dx.doi.org/10.1093/applin/aml029

Long, M. H. (1985). A role for instruction in second language acquisition: Task-based language teaching. In K. Hyltenstam, \& M. Pienemann (Eds.), Modelling and assessing second language acquisition (pp. 77-79). Clevedon, England: Multilingual Matters.

Mayer, R. E. (2004). Should there be a three-strikes rule against pure discovery learning: The case for guided methods of instruction. American Psychologist, 59(1), 14-19. http://dx.doi.org/10.1037/0003-066X.59.1.14

Mayer, R. E. (2009). Multimedia Learning (2nd ed.). Cambridge University Press.

Mehnert, U. (1998). The effects of different lengths of time for planning on second language performance. Studies in Second Language Acquisition, 20, 83-108.

Moreno, R., \& Mayer, R. (2007). Interactive multimodal learning environments. Educational Psychology Review, 19, 309-326. http://dx.doi.org/10.1007/s10648-007-9047-2

Nunan, D. (2004). Task-based Language Teaching. Cambridge language teaching library.

Ortega, L. (1999). Planning and focus on form in L2 oral performance. Studies in Second Language Acquisition, $21,109-148$.

Pang, Y. M. M. (2009). Provision of English language education in small class settings: Reconsidering content, thinking and language use in ELT. Paper presented at The International Conference on Primary Education 2009, Hong Kong.

Robinson, P. (2001) Task Complexity, Task Difficulty, and Task Production: Exploring Interactions in a Componential Framework. Applied Linguistics, 22(1), 27-57. http://dx.doi.org/10.1093/applin/22.1.27

Robinson, P. (2003b). The cognition hypothesis, task design, and adult task-based language learning. Second Language Studies, 21(2), 45-105.

Robinson, P. (2005a). Cognitive complexity and task sequencing: Are view of studies in a componential framework for second language task design. International Review of Applied Linguistics in Language Teaching, 43(1), 1-33. http://dx.doi.org/10.1515/iral.2005.43.1.1

Robinson, P. (2007). Task complexity, theory of mind, and intentional reasoning: Effects on L2 speech production, interaction, uptake and perceptions of task difficulty. IRAL, 45, 193-213. http://dx.doi.org/10.1515/iral.2007.009

Robinson, P. (2011). Task-based language learning: A review of issues (pp. 1-36). In P. Robinson (Ed.), Task-based Language Learning. Library of Congress Category-in-publication data. http://dx.doi.org/10.1111/j.1467-9922.2011.00641.x

Saville-Troike, M. (2012). Introducing Second Language Acquisition. Cambridge University Press. 
Schmidt, R. (1992). Psychological mechanisms underlying second language fluency. Studies in Second Language Acquisition, 14, 357-385. http://dx.doi.org/10.1017/S0272263100011189

Skehan, P., \& Foster, P. (1997). Task type and task processing conditions as influences on foreign language performance. Language Teaching Research, 1(3), 185-211. http://dx.doi.org/10.1177/136216889700100302

Skehan, P., \& Foster, P. (1999). The influence of task structure and processing conditions on narrative retellings. Language Learning, 49, 93-120. http://dx.doi.org/10.1111/1467-9922.00071

Skehan, P., \& Foster, P. (2001). Cognition and tasks. In P. Robinson (Ed.), Cognition and second language instructions (pp. 183-205). Cambridge: Cambridge University Press.

Skehan, P., \& Foster, P. (2005). Strategic and online planning: The influence of surprise information and task time on second language performance. Language Teaching Research, 1, 185-211.

Yuan, F., \& Ellis, R. (2003). The effects of pre-task planning and on-line planning on fluency, complexity, and accuracy in L2 monologic oral production. Applied Linguistics, 24(1), 1-27. http://dx.doi.org/10.1093/applin/24.1.1

Wood, D. (2010). Formulaic language and second language speech fluency. Background, Evidence and Classroom applications-Continuum International Publishing Group.

\section{Appendices}

Appendix 1

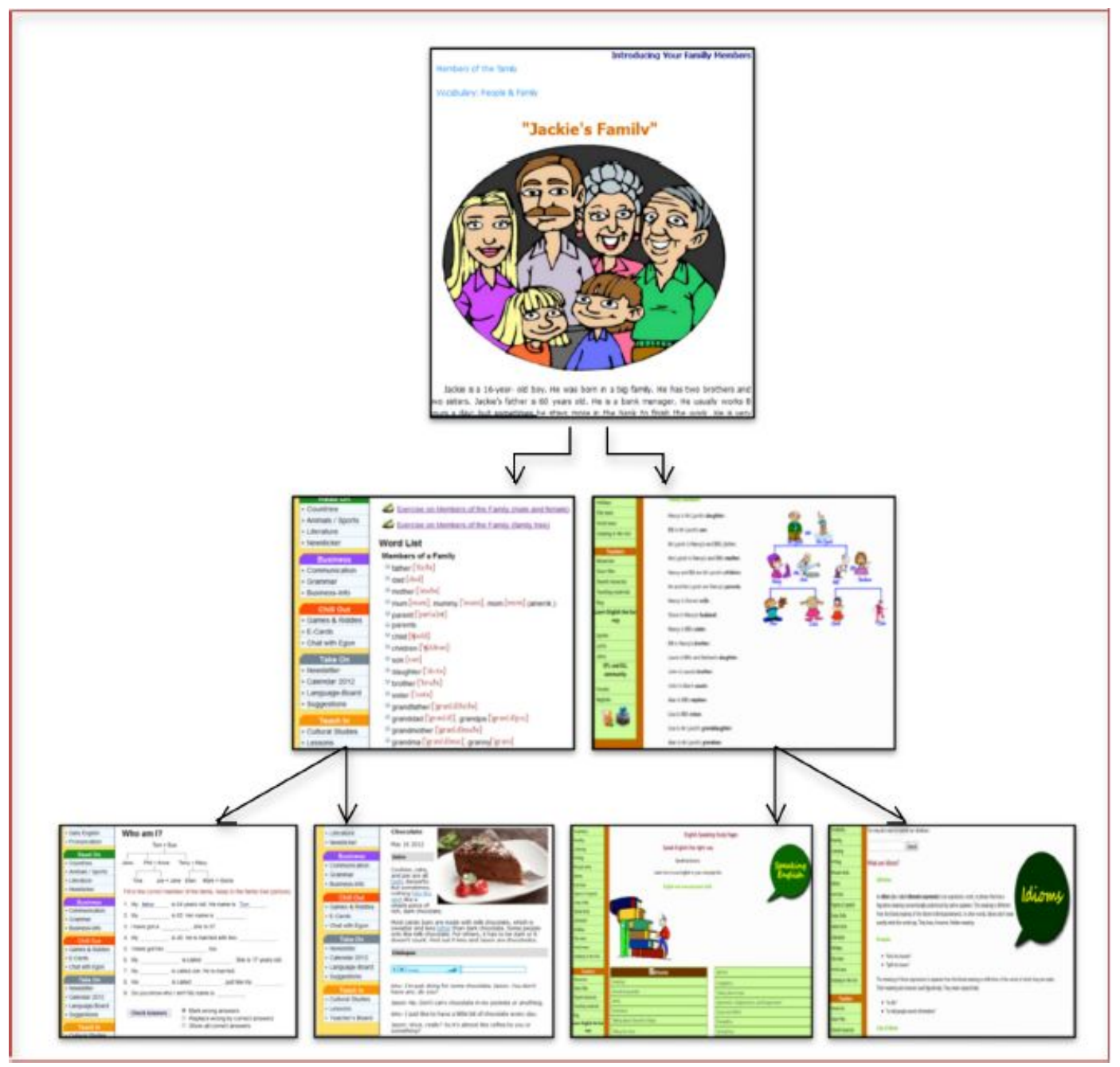

Multimedia Instructional Materials 
Appendix 2

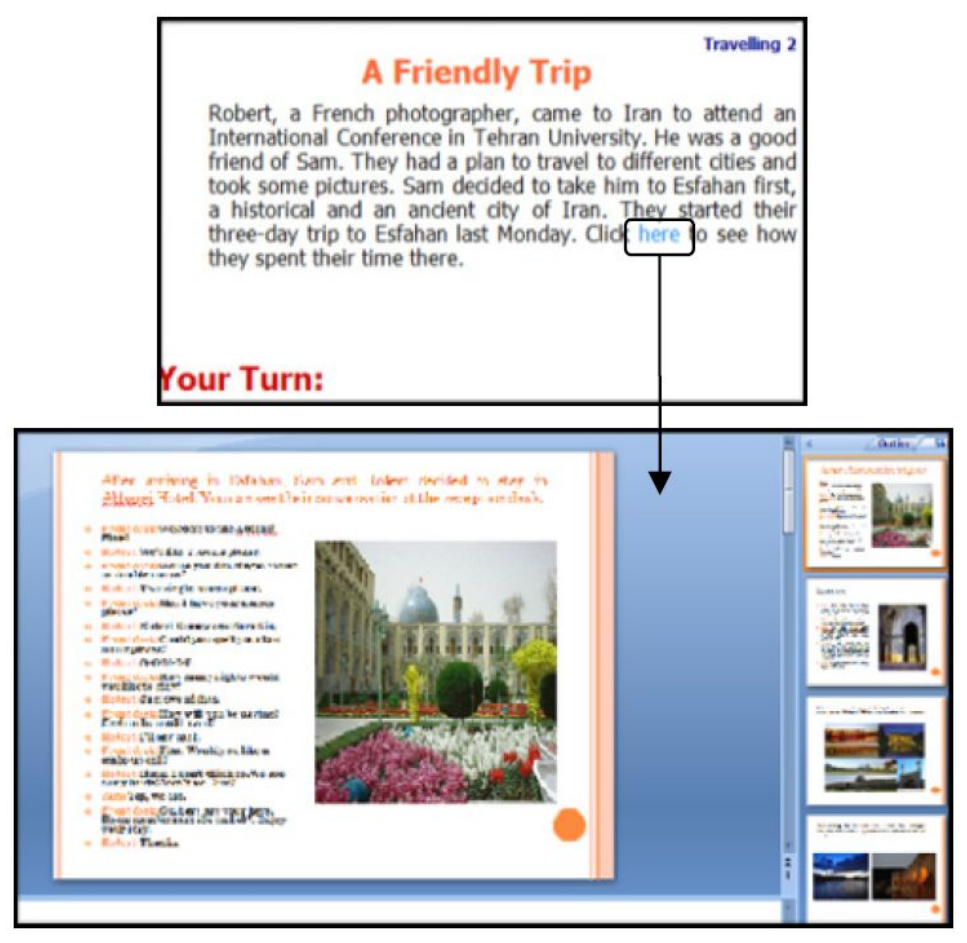

Hypertext in a unit of study

Appendix 3

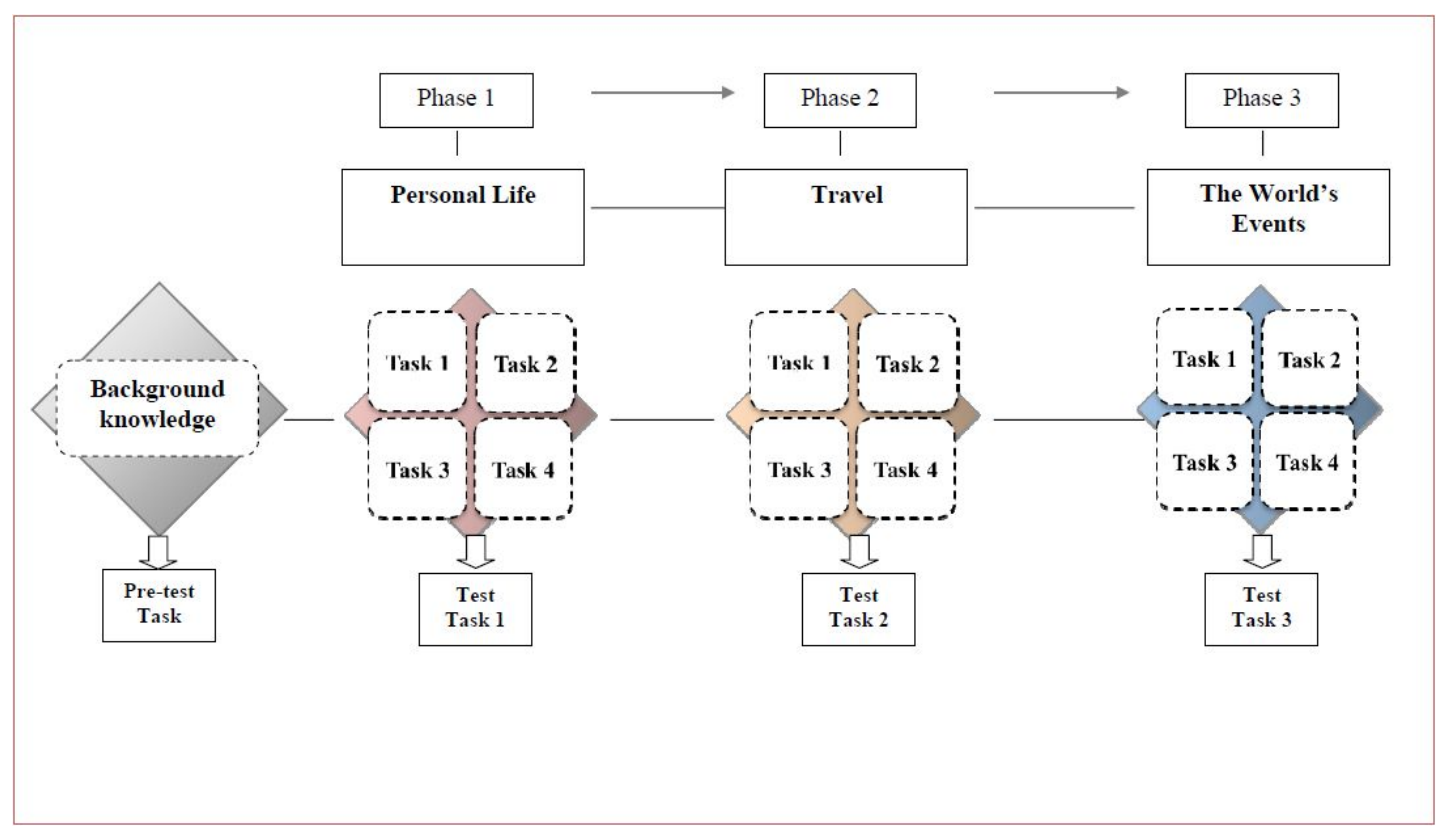

\section{Copyrights}

Copyright for this article is retained by the author(s), with first publication rights granted to the journal.

This is an open-access article distributed under the terms and conditions of the Creative Commons Attribution license (http://creativecommons.org/licenses/by/3.0/). 